Article

\title{
An Analysis of Heterogeneity in German Speaking Birdwatchers Reveals Three Distinct Clusters and Gender Differences
}

\author{
Christoph Randler (ID
}

check for updates

Citation: Randler, C. An Analysis of Heterogeneity in German Speaking Birdwatchers Reveals Three Distinct Clusters and Gender Differences. Birds 2021, 2, 250-260. https:// doi.org/10.3390/birds2030018

Academic Editors: Michał Ciach and Jukka Jokimäki

Received: 27 June 2021

Accepted: 26 July 2021

Published: 29 July 2021

Publisher's Note: MDPI stays neutral with regard to jurisdictional claims in published maps and institutional affiliations.

Copyright: (C) 2021 by the author. Licensee MDPI, Basel, Switzerland. This article is an open access article distributed under the terms and conditions of the Creative Commons Attribution (CC BY) license (https:// creativecommons.org/licenses/by/ $4.0 /)$.
Department of Biology, Eberhard Karls University Tuebingen, Auf der Morgenstelle 24 D-72076 Tuebingen, Germany; Christoph.randler@uni-tuebingen.de

Simple Summary: Birdwatching is an increasingly popular leisure activity that combines nature experience with cognitive challenges, such as identifying birds in the field. In this study, we assessed whether birdwatchers can be segmented into different clusters or types. Members from a wide range of bird related organizations, from highly specialized birders as well as Facebook bird group members, were studied to provide a diverse dataset ( $n=2766 ; 50.5 \%$ men). Birding specialization was measured with a battery of questionnaires. Birding specialization contains the three dimensions of (i) skill/competence, (ii) behavior, and (iii) personal and behavioral commitment. Additionally, involvement in this activity, measured by centrality to lifestyle, attraction, social bonding, and identity, was used. The NbClust analyses showed that a three-cluster solution was the optimal solution. Then, k-means cluster analysis was applied on three groups: casual/novice, intermediate, and specialist/advanced birdwatchers. More men than women were in the specialist/advanced group and more women than men in the casual/novice group. As a conclusion, this study confirms a three-cluster solution for segmenting German birdwatchers based on a large and diverse sample and a broad conceptualization of the construct birding specialization. These data may be helpful when addressing different target audiences with different programs, e.g., in nature conservation.

Abstract: The purpose of this study was to segment birdwatchers into clusters. Members from a wide range of bird related organizations, from highly specialized birders as well as Facebook bird group members were studied to provide a diverse dataset $(n=2766 ; 50.5 \%$ men). Birding specialization was measured with a battery of questionnaires. Birding specialization encompassed the three constructs of skill/competence, behavior, personal and behavioral commitment. Additionally, involvement, measured by centrality to lifestyle, attraction, social bonding, and identity, was used. The NbClust analyses showed that a three-cluster solution was the optimal solution. Then, k-means cluster analysis was applied on three groups: casual/novice, intermediate, and specialist/advanced birdwatchers. More men than women were in the specialist/advanced group and more women than men in the casual/novice group. As a conclusion, this study confirms a three-cluster solution for segmenting German birdwatchers based on a large and diverse sample and a broad conceptualization of the construct birding specialization. These data can be used to address different target audiences (novices, advanced birders) with different programs, e.g., in nature conservation.

Keywords: birding; birdwatching; citizen science; recreation specialization; German

\section{Introduction}

Birdwatching is considered to be a non-consumptive leisure activity with recreational specialization [1]. Non-consumptive behavior distinguishes birdwatching from other nature-related activities like bird hunting, game hunting, and fishing/angling. Specialization analysis of, e.g., groups such as wildlife tourists, is associated with specific behaviors, motivations, perceptions, and satisfaction [2]. In this study, we explicitly did not define a priori what a birdwatcher or birder is, but we tried to depict the variety of birding activities 
by covering a wide range of bird-related organizations, including non-formally organized birdwatchers. Other studies started with a clearly defined description of birdwatchers and excluded all people that did not fit into sometimes rather narrow definitions, which neglects other types of birdwatching, such as people watching birds at their feeders in the garden. On the other side, the highly cited study of Kellert [3] posed an extremely wide definition, whereby everybody looking at a bird could define himself/herself as a birdwatcher, which led to an exorbitantly high proportion of birdwatchers in the USA. Here, I bridged the gap between these two approaches by following a variety of concepts of recreation specialization.

\section{Review of Literature}

\subsection{Recreation Specialization}

Recreation specialization represents a continuum in behavior between the generalists with low involvement and the specialists with high involvement [4,5]. Leisure specialization comprises the following facets: (i) investment in leisure activities, (ii) knowledge about the activity, (iii) the activity itself, and (iv) the degree of specialization [4]. It also includes an attitudinal component [5]. Scott and Shafer [1] refined this into a three-dimensional construct with a behavioral, a cognitive, and an affective component [6]. Indicators for the behavioral component are equipment, previous participation, and experience. Indicators of the cognitive dimension include the level of competence and knowledge of the activity. Indicators of affective attachment and engagement include lifestyle centrality and continued participation [2]. Based on these variables, people could be arranged along a continuum, suggesting that beginners may have a low level of competence and skill, invest less time and money, and the recreation activity is not as central to their lifestyle compared to highly specialized people [2].

However, recreation specialization is not a stable trait, because it also focuses on progression, which means that a person can become more specialized over time $[4,5]$. Scott and Shafer [1] emphasized the developmental process that entails progression in terms of (i) a focusing of behavior, (ii) the acquiring of skills and knowledge, and (iii) personal and behavioral commitment. However, the trajectories of these three aspects might not develop concurrently. Some individuals may show a high degree of skill/competence but participation in the activity is infrequent. Other individuals may participate more often but demonstrate little progression in the way of skill development [1].

Another aspect of commitment is centrality to lifestyle, which has a psychological and a behavioral component [7]. Centrality to lifestyle can be viewed as part of the larger construct of involvement [8]. Social-psychological involvement is a state of motivation, arousal, or interest with regard to a product, an activity, or an object [9]. Kyle et al. [8] present a measurement model with five correlated dimensions of involvement: attraction, centrality to lifestyle, social bonding, identity affirmation, and identity expression.

Here, German speaking birdwatchers have been in the focus of the study. While in the USA and Canada, birders have been under study for a long time (e.g., [3,6,10-24]), there are no scientific studies about German speaking birders. This is probably related to the fact that hunting and fishing and associated conservation expenditures tend to be more popular in North America [25]. Only a few studies were outside this area, e.g., in a national park in Thailand [7], in Taiwan [26], Hong Kong [27], Portugal [28], South Africa [29], or Poland [30]. Recently, Hermes et al. [31] quantified the nature-based recreation cost in Germany as $€ 151.3$ billion, including travel costs, on-site expenses, and opportunity costs, suggesting that birding is an emerging market in Germany. Therefore, segmenting birdwatchers from this region represents a means to classify people into different categories and to develop and adapt programs for different people. For the study of German speaking birdwatchers, the recreation specialization and the involvement concepts were applied. As there is no previous study in German speaking birdwatchers and only a few studies in Europe, a wide range of concepts and measurements (as described above) has been employed to characterize birdwatchers. 


\subsection{Recreation Specialization in and Categorization of Birdwatchers}

The framework of recreation specialization has been adapted to a variety of wildlifebased outdoor recreation groups, including birdwatchers in Alberta, AB, Canada [16], anglers [32], and hunters [33]. McFarlane [16] used the factors of experience, economic commitment, and centrality to lifestyle to group birders into four categories: casual, novice, intermediate, and advanced birders. Further, McFarlane and Boxall [18] showed that birders support conservation activities, and that activities such as memberships or donations increase with a higher specialization level. McFarlane [17] further showed that birdwatchers progress through stages of development and change their attitudes, preferences, and group affiliations over time.

Hvenegaard [7], studying birder tourists in Thailand, used cluster analysis, based on experience, economic commitment, and centrality to lifestyle, to categorize birders into three distinct groups: advanced-experienced $(10 \%)$, advanced-active $(50 \%)$, and novices $(40 \%)$. The difference between advanced-active birders and advanced-experienced birders was that the former spent more days birding than advanced-experienced and scored higher on centrality to lifestyle [7]. During the Texas birding festival, Scott and Thigpen [22] identified four groups of birders, namely casual birders, interested birders, active birders, and finally skilled birders. Interested birders could identify about 40 bird species, and scored low on the centrality items, while active birders spent more time on trips, and had a high knowledge and were able to identify about 125 species. However, skilled birders could identify more than 300 species [22]. Later on, Scott et al. [24], studying birders during crane migration in Nebraska, reduced the categories into three, namely committed, active, and casual birdwatchers. Similarly, Harshaw et al. [12] studied eBird users in the whole USA and identified three clusters. Lessard et al. [15] excluded novice birdwatchers from their analysis in Alabama birders and revealed two distinct clusters, which in turn also led to a three factor-solution. In a further conceptualization, extremely specialized birdwatchers were defined as a group of "hard core" birdwatchers [21]. These individuals practice birding as form of serious leisure, i.e., they show extraordinary commitment to their activity in terms of time and money spent [21].

Furthermore, some relationships between level of specialization and other outcomes were identified. For example, in Chinese birdwatchers in Hong Kong, Cheung et al. [27] reported a positive association between the birdwatchers' specialization and pro-environmental attitudes and an indirect positive association between their specialization and ecologically responsible behaviour. Lessard et al. [15] found that a higher specialization level was positively related to awareness, knowledge, and conservation attitudes.

In a particular case, participants of birdwatching events have been studied. Scott et al. [23] studied participants in the First Annual Great Texas Birding Classic. This event involved three days of birding along three sections of the Texas coast and attracted elite or "hard core" birders, with a high proportion of participants (72\%) with a "life list" (total number of birds observed in their life) encompassing an average of 1139 species [23]. A special case has been described in birdwatchers that travel long distances to see rarities [34]. This behavioral commitment falls within the definition of "hard core" birdwatching.

Previous studies using cluster analysis revealed three or four clusters of birdwatchers ([29]; UK and NL). Three clusters were suggested by $[7,12,16,22,24]$. These studies demonstrate a considerable effort in segmenting and describing birdwatchers. However, studies differ in the number of clusters they applied, the breadth of the constructs measured, and the variety of the population sampled. Not all studies were based on a statistical approach to assess the optimal number of clusters. Sometimes it was a pre-defined number of clusters, defined, e.g., by previous studies or personal experience.

\subsection{Gender Differences in Birdwatching}

Concerning gender, men usually display a higher level of specialization. For example, McFarlane and Boxall [18] found that females formed $60 \%$ of casual birdwatchers, but only $37 \%$ of more specialized birders. Similarly, male members of the Carolina Birding Club 
reported higher skills and more expensive birdwatching equipment [19]. Scott et al. [24], studying members of the American Birding Association (ABA), found males participating more frequently, travelling longer distances, and reporting higher skills than females. However, there was no difference between genders concerning the level of commitment. Cooper and Smith [10] analyzed gender patterns across organizations in the USA and the UK. These authors reported that gender differences in preferred types of bird-related recreation mirrored gender-specific differences in preferences for competition. They found observing birds as a recreational hobby, termed "bird watching", was more female biased, and that the competitive sport, "birding", was heavily male biased [10]. This was confirmed by Scott et al. [23] who reported that $85 \%$ of participants in a competitive birdwatching event were male.

\section{The Current Study}

Previous studies focused either on special groups, or on subsets of birders, such as members of a specific organization, e.g., the American Birding Association [6], or on visitors of a birdwatching fair [23]. Only a few studies, such as Eubanks et al. [11], assessed different subpopulations of birdwatchers. In this study, the main aim was to cover a wide, heterogenous range of birdwatchers from nearly the full range of formal organizations, such as scientific state and countrywide organizations, nature conservancy organizations, as well as Facebook groups including birdwatchers that are not formally institutionally organized. Further, a special focus was to include hard-core birders who are organized in a special club (club300). Thus, this is the first study covering such a wide range of birdwatchers. Previous studies focusing on birder segmentation revealed usually three or four clusters, thus it is unclear whether birders should be separated into three or four clusters (see above).

The purpose of this study was to segment birdwatchers into clusters and to assess the number of valid clusters. Therefore, an objective method to assess the number of clusters was applied, followed by a k-means cluster analysis to segment the studied population of birdwatchers into groups. To add to the quality of the study and to comprehensively assess the difference between clusters of birdwatchers, I applied a battery of measures that have been used in recent studies, rather than focusing on a small number of scales. Therefore, scales on the three dimensions, i.e., skill/competence, behaviour, and commitment, that stem from the concept of recreational specialization [1], have been included, as well as involvement with its dimensions, attraction, centrality to lifestyle, social bonding, and identity [8]. Finally, as gender differences have been documented in many studies, an additional analysis was applied to check if the given clusters established in this study portray the same well-known gender differences of previous work to add to the validity of the cluster solution.

\section{Materials and Methods}

\subsection{Sample}

Data for this study were collected via the Online Research Tool SoSciSurvey between 14 February 2020 and 15 June 2020. On the first webpage, aims of the study were explained, and a formal consent was asked for. Participants had to actively click on "yes" to start the study. They were also able to stop and leave at any time. Participants were recruited via many channels, e.g., using announcements on the webpages of large bird and naturerelated organizations (Naturgucker; NABU; DO-G; club300). Mailing lists were used from some organizations (Naturgucker). All regional chapters of the DDA (German organization of field ornithologist societies) were asked for participation by posting on their websites or by distributing the link on their mailing lists. The DDA covers about 50 organizations, where some of them represent the federal state, some only parts of the federal states, or regional chapters. The German society for scientific ornithology was contacted, which includes scientifically interested and knowledgeable birdwatchers. The Club300 represent the most interested and skilled observers. Their previous criterion to become a member 
was to have seen at least 300 different bird species in Germany. NABU posted the study on the website, which is the largest nature conservation non-profit society in Germany with a focus on birds (BirdLife, Berlin, Germany) because it emerged from the German Society for bird conservation. In addition, Facebook groups with a relation to birdwatching were used to post information about the study. Finally, an advertisement was published in a printed birdwatching journal to target more classical readers. The aim was to cover a wide variation of birdwatchers of different organizations in German speaking countries (Germany, Austria, Switzerland), from people preferring backyard birdwatching, to highly specialized birders and (semi-)professionals. The study was granted permission by the ethics committee of the Faculty for Economics and Social Sciences.

\subsection{Measurements}

\subsubsection{Demographics}

Demographic data were age (in years), gender (male, female, diverse, prefer not to answer), and highest formal qualification.

\subsubsection{Birding Specialization}

Birding specialization was measured with an array of previously published instruments (see below). The questionnaires were translated from English to German by three fluent German speakers with nine years of English independently from each other (parallel translation method). After the translation, the three versions were compared, and any German questions were discussed by the research team before a final translation was agreed upon.

\subsubsection{Skill and Competence}

Skill and competence included a self-report of the number of species a person is able to identify without a field guide by appearance (e.g., from $[6,15,27])$ and by song without a field guide [6,15]. Self-assessed knowledge from 1 (novice) to 5 (expert) was adapted from $[6,27]$ but transformed to a five-point Likert scale. This scale contained open-ended questions. The open-ended questions were z-transformed prior to analysis. This was done because the range was from 0 to 1000 different species. Cronbach's $\alpha$ of the skill/competence scale was 0.844 .

\subsubsection{Behavior}

This scale refers to self-reported real behavior. Behavior contained the number of birding trips taken last year (at least $2 \mathrm{~km}$ away from home; [6,18]), number of days spent for birding last year $[6,7,27,28]$, number of bird species on lifelist [26], number of bird books owned [16], replacement value of the total equipment [7,26,27], and number of species on a national list (this study). Open-ended questions were z-transformed prior to analysis. Cronbach's $\alpha$ of the behavior scale was 0.780 .

\subsubsection{Personal Commitment}

Personal commitment was measured with three questions: "Other leisure activities don't interest me as much as birding." [6,9,19]; "I would rather go birding than do anything else." $[13,19,20]$ and "Others would probably say that I spend too much time birding." [13,19]. All items were measured on a five-point Likert scale. Cronbach's $\alpha$ of the personal commitment scale was 0.757 .

\subsubsection{Behavioral Commitment}

This scale refers to psychological aspects of behavioral commitment. Three items were used on a five-point Likert scale. "If I couldn't go birding, I am not sure what I would do." [6,19]; "If I stopped birding, I would probably lose touch with a lot of my friends." [13,19] and "Because of birding, I don't have time to spend participating in other leisure activities." [13,19]. Cronbach's $\alpha$ of the behavioral commitment scale was 0.709 . 


\subsubsection{Involvement}

Involvement was assessed with the modified involvement scale [8]. Three items each measured "attraction" (Cronbach's $\alpha=0.858)$, "centrality to lifestyle" (Cronbach's $\alpha=0.857$ ), and "social bonding" (Cronbach's $\alpha=0.785$ ). Identity was measured with one item ("Birdwatching is an important part of my identity." [15]).

\subsection{Statistical Analysis}

We used only participants with $15 \%$ missing data or less, meaning that the participants filled $85 \%$ of the questions of the questionnaire A total of 2809 people participated in the study. Mahalanobis distance was calculated to identify outliers and tested against a chisquare distribution. Further, 43 outliers were removed because their Mahalanobis distances differed highly significantly from the chi-square distribution (with a $p<0.001$ ), suggesting their exclusion to make a multivariate analysis feasible. The NbClust package [35] in R [36], which provides various indices was used to determine the number of clusters for further statistical analysis. The package proposes the best number of clusters depending on the results of different clustering methods. For this study, we used 24 different clustering indices and "Ward.D2" as a distance measure to compute a dissimilarity matrix. Afterwards, $\mathrm{k}$-means cluster analysis was applied to cluster the individuals into groups using SPSS 26. To compare gender distribution across the three clusters, a $\chi^{2}$ test was applied, and standardized residuals were examined. To compare the means of the continuous measures of specialization, a multivariate general linear model was applied with partial eta-squared as a measure of effect size. Post-hoc comparisons were performed with univariate analyses in SPSS 26 (IBM Corp., Armonk, NY, USA).

\section{Results}

A total of 2766 birdwatchers participated in this study (1396 men (50.5\%), 1357 women, and 13 diverse). Mean age (mean \pm SD) was $46.89 \pm 15.88$. Women in our sample were slightly younger than men (mean \pm SD: men: $48.10 \pm 16.95$; women $45.74 \pm 14.62, t$-test: $\mathrm{T}=3.903, \mathrm{df}=2747, p<0.001)$. Most participants were from Germany $(n=2648), 73$ from Austria, 44 from Switzerland, and one from Luxembourg. $n=242(8.7 \%)$ reported to have a PhD as a highest degree, $n=1309(47.3 \%)$ had a bachelor or master's degree from a university, $n=535$ (19.3\%) had Matura (university entrance exam; $12-13$ years of schooling), $n=480$ (17.4\%) were from middle stratification level (10 years of schooling) and $n=127(4.6 \%)$ reported nine years of schooling. Finally, $n=73(2.6 \%)$ reported a different degree. Descriptive statistics of the scales are presented in Table 1.

Table 1. Descriptive statistics for the sample. Scales are shown. Please note skill/competence and behavior haven been z-standardized.

\begin{tabular}{ccccc}
\hline Scale & Min & Max & Mean & SD \\
\hline attraction & 1 & 5 & 3.856 & 0.827 \\
centrality & 1 & 5 & 2.829 & 1.087 \\
social bonding & 1 & 5 & 2.312 & 0.847 \\
identity & 1 & 5 & 2.980 & 1.203 \\
skill/comp & -1.13 & 3.64 & -0.044 & 0.775 \\
behaviour & -0.69 & 3.38 & -0.034 & 0.637 \\
personal commitment & 1 & 5 & 2.595 & 0.934 \\
behavioral commitment & 1 & 5 & 1.689 & 0.679 \\
\hline
\end{tabular}

The number of proposed clusters varied between three and five. Overall, among all indices, 12 methods proposed three as the best number of clusters, 10 proposed four and two proposed five as the optimal number of clusters. Hence, according to the majority rule, the best number of clusters was three and this was used for further analysis. Therefore, the k-means cluster analysis was based on a three-factor solution (Table 2, Figure 1). Cluster 2 showed below average values in all variables representing casual or novice 
birdwatchers, cluster 3 represents the specialists or advanced, while cluster 1 represents the intermediate birdwatchers. Moreover, 1110 were classified in the casual/novice group, 1090 as intermediate, and 566 as specialist/advanced. Checking the three-cluster solution against the continuous measures of specialization revealed significant differences in a multivariate general linear model (Wilk's $\lambda=0.139, p<0.001$ ) with a high effect size of 0.627 (partial eta-squared). All post-hoc comparisons between the three clusters were significant at a 0.001 level in all eight continuous measures. Women and men differed in their categorization $\left(\chi^{2}=274.362, \mathrm{df}=2, p<0.001\right.$; Figure 2$)$. An inspection of the standardized residuals from the $\chi^{2}$ test showed that there are no differences between the number of men and women in the intermediate group, while more women than men were in the casual/novice group and, in turn, more men than women in the specialist/advanced group.

Table 2. Results of the three-cluster solution. Mean values of the recreation specialization sales are shown according to the cluster solution of intermediate, casual/novice and specialized birdwatchers. A higher score represents a higher specialization.

\begin{tabular}{cccc}
\hline & \multicolumn{3}{c}{ Cluster } \\
\cline { 2 - 4 } & $\mathbf{1}$ & $\mathbf{2}$ & $\mathbf{3}$ \\
& Intermediate & Casual/Novice & Specialist \\
\hline skill/competence & -0.06818 & -0.60861 & 1.32486 \\
behaviour & -0.09609 & -0.61625 & 1.39359 \\
personal commitment & 0.23353 & -0.81382 & 1.14628 \\
behavioral commitment) & 0.09335 & -0.72435 & 1.24076 \\
attraction & 0.36508 & -0.85316 & 0.97008 \\
centrality & 0.28219 & -0.92235 & 1.26542 \\
social bonding) & 0.06532 & -0.62740 & 1.10462 \\
identity & 0.29632 & -0.85341 & 1.10300 \\
\hline
\end{tabular}

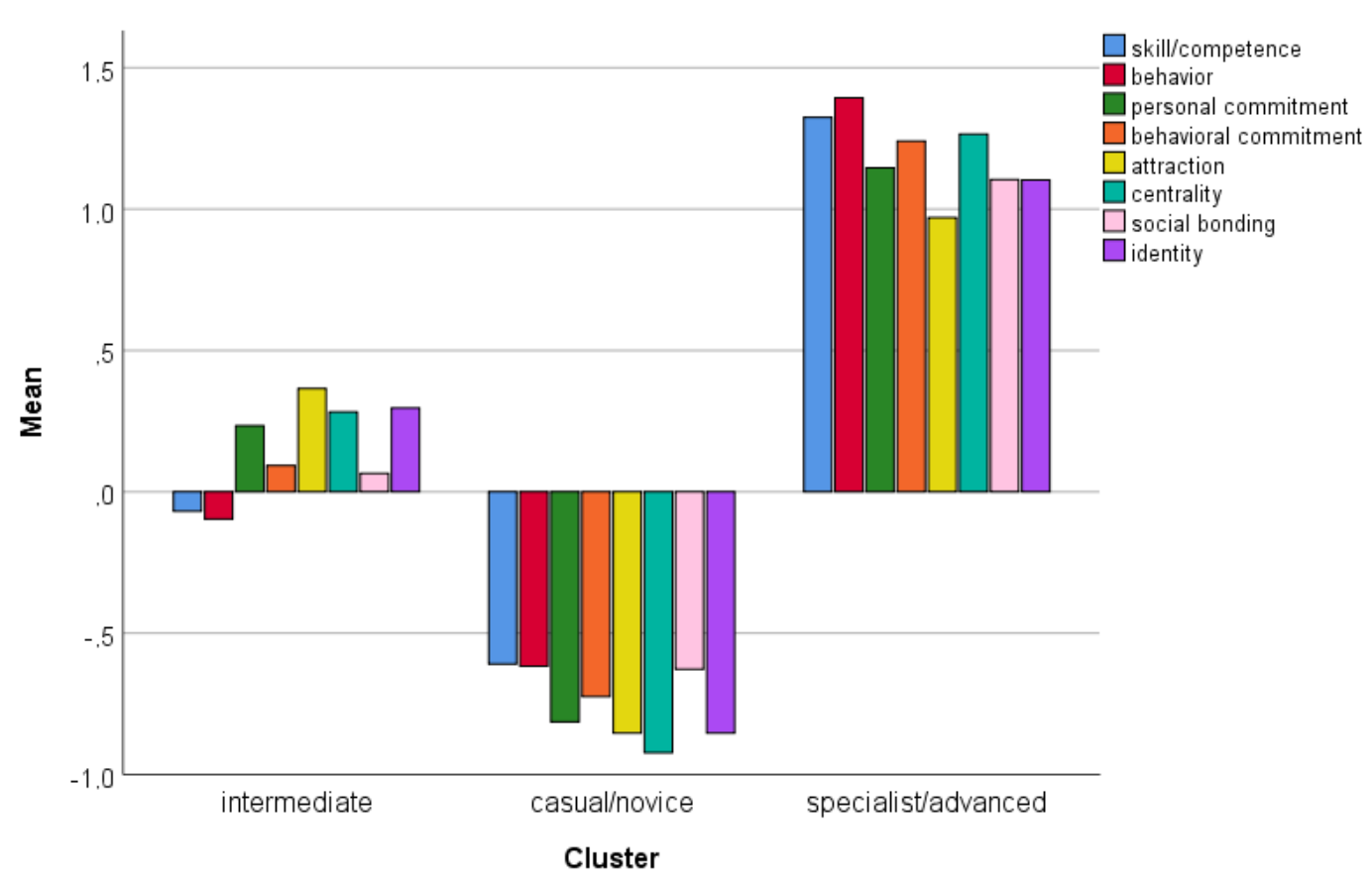

Figure 1. Distribution of the scores of the eight continuous measures of birding specialization (see legend) according to the three clusters. A higher value represents a higher specialization. 


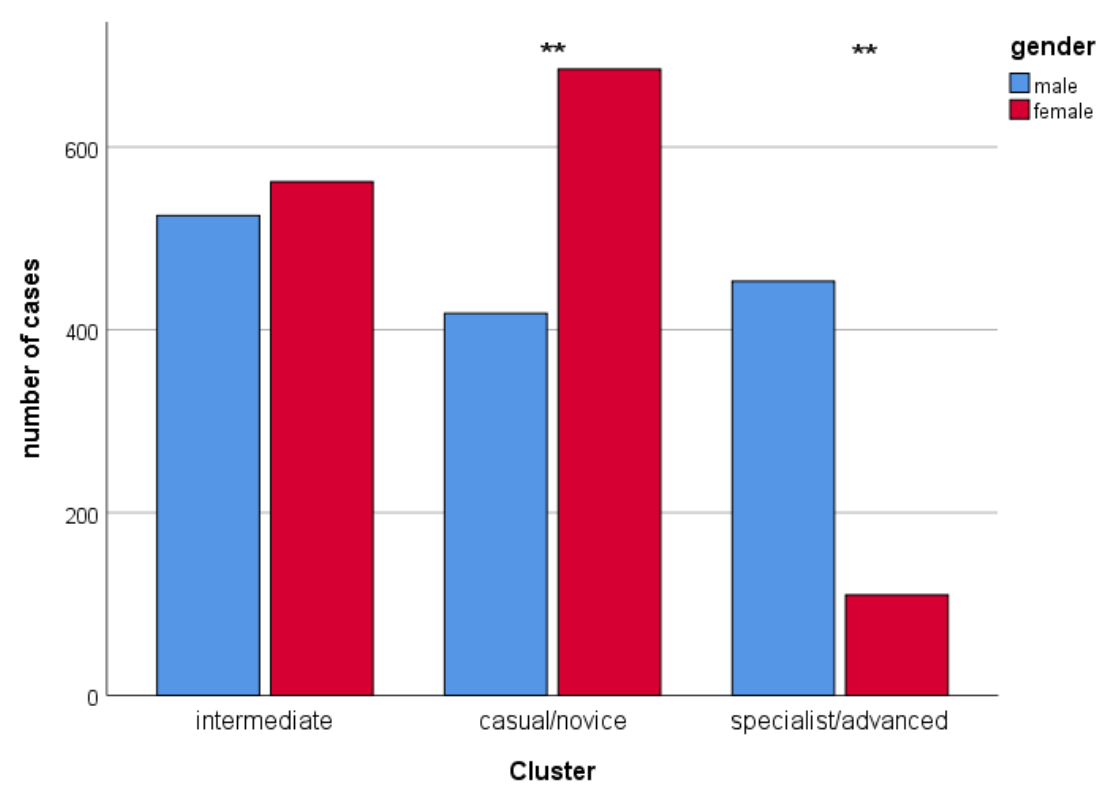

Figure 2. Distribution of the three clusters (intermediate, casual/novice and specialist/advanced) among gender. ${ }^{* *}$ denote significant differences $(p<0.01)$.

\section{Discussion}

This study presents results from a large cross-sectional sample of birdwatchers reaching different levels of recreation specialization. Concurrent with other studies, our sample was slightly older (47 years) than the mean in Germany (44.2 years; [37]). However, mean age was much lower than in other comparable studies, e.g., in [22] where 75\% were over 45 years, or in [16] with an age range between 48 and 54 years. One reason for this might be that birdwatching as a leisure activity may have attracted younger people during the last decade(s). However, there are no data supporting this claim. Also, the birdwatchers in this study showed a high degree of education, with nearly $10 \%$ holding a PhD degree. This has been found in some other studies as well [22]. Thus, birdwatching in German speaking countries might be a leisure activity for older and more educated people. The comparison with other places or countries is difficult, because only a few studies covered such a wide range of birdwatchers, and many focused on specific events, places, or are some decades old. Accordingly, the change in this leisure activity, probably reflected in the increasing participation of younger and female people cannot be assessed, and it is unclear whether the German speaking population differs or just reflects the changes in a general development.

\subsection{Heterogeneity and Specialization}

In this study, we segmented birdwatchers by cluster analysis and found support for a three-cluster solution, including casual/novice, intermediate, and specialist/advanced birdwatchers. Previous work also revealed a three-cluster solution, but the studies differed to some extent from the present one. For example, Lessard et al. [15] did not apply the specialization measures when people have classified themselves as novices. Although this might be adequate from a pragmatic viewpoint, valuable data are dispensed. Harshaw et al. [12] made a sophisticated analysis to identify three distinct groups of birders. However, their data are based on eBird participants only (despite a large sample size), but users of citizen science platforms differ from non-using birdwatchers in many aspects [38]. Hence, a strength of the present study is that it includes a wide range and diversity of birdwatchers.

Concerning subpopulations of birdwatchers, Eubanks et al. [11] strongly suggested to analyze a wide range of birdwatchers rather than focusing on a special subgroup, e.g., a geographic subpopulation. This was accomplished in the present study as it covers the 
complete geographic region of the German speaking countries Austria, Germany, and Switzerland. Furthermore, all federal states of Germany are represented in this study.

Specialization can be measured by different approaches. One is the construct developed by Lee and Scott [6]. These authors focused on skill/competence, behavior, and psychological commitment (both personal commitment and behavioral commitment). Other approaches focused more on the broader construct of involvement [8], which includes centrality of lifestyle, attraction, identity, and social bonding. These different approaches are all included in the present study. Recent research suggests that these two approaches might not be distinct phenomena [12]. Harshaw et al. [12] used a second order factor analysis and proposed a model in which birding specialization consists of three constructs, namely cognitive (which is equivalent to the skill/competence construct of [6]), behavior, which encompasses aspects of equipment, or frequency of participation, which also reflects the behavior component of Lee and Scott [6]. Finally, they propose an affective component, which is mainly based on centrality of lifestyle and attraction.

\subsection{Gender Differences}

Gender differences were significant in birding specialization, with more men than women being in the specialist/advanced group and more women than men in the casual/novice cluster. This is comparable to other studies. Cooper and Smith [10] analyzed gender patterns across organizations in the US and the UK. These authors reported that gender differences in preferred types of bird-related recreation mirrored gender-specific differences in preferences for competition. They found observing birds as a recreational hobby, termed "bird watching", was more female biased, and that the competitive sport, "birding", was heavily male biased [10]. This was confirmed by [23]. A difference between men and women in skill/competence has been found in previous studies. Men were more involved in birding in terms of their objective behavior and skill level [19]. Differences in behavior (trips taken, days spent birding) have also been reported in previous studies [24]. The higher scores of men in skill/competence and behavior accord well with the results of Cooper and Smith [10], who reported a focus on higher competition among men, because skill/competence is related to the number of bird species that can be identified. Similarly, behavior was related to the number of birding trips or days spent birding. Thus, gender differences in German birdwatchers are similar compared to studies from other countries.

Gender differences are often explained with two reasons. First, it may be part of our evolutionary history, such that the hunting of animals may probably persist in the leisure activity of "hunting" birds with binoculars. The second explanation is related to the social world, e.g., nurture, education, and socialization. In this case, gender differences are not stable, but change over time, and we can predict that, in the future, the amount of female specialist birdwatchers should increase proportionally (see, e.g., for gender differences in animal attitudes [39]).

\subsection{Practical Implications}

The higher age of the birdwatchers found in Germany should be taken into account when planning conservation efforts. For example, older people may me more reluctant to use web-based solutions for data collection and reporting, such as citizen science platforms [38]. Therefore, tailoring programs to different age groups may be worthwhile.

The highly specialized cluster may be self-maintaining because of members' high knowledge and commitment, but there should be a special target on the audience of novice or casual birders, who may benefit from web-based support. Taking these novices by the hand and helping them to develop their skills surely requires in-person contact or assistance, so for the group of prospective intermediates, personal contact may help. For conservation efforts, many venues need to be addressed, because younger birders may prefer internet information and exchange, while older people might be better reached by leaflets or magazines. 
Continued involvement could be fostered in different ways, such as competition for higher specialized birders, but BioBlitzes should also be used to address intermediates because intermediate birders have sufficient knowledge to work on such conservation or scientific aspects.

\subsection{Limitations}

Based on the methods, there are still types of birdwatchers who are still not going to be included in the sample (e.g., older birdwatchers who do not use the internet). Further, more comprehensive studies might also include a range of people being studied during a birdwatching fair or during local club meetings and congresses.

\subsection{Conclusions}

Previous work used self-reporting as a classification variable to group birders into usually 3-4 groups that could be placed alongside of a continuum of recreation specialization. Based on a large and diverse sample, a variety of measures, and complex statistical analysis to establish the number of clusters, a three-cluster solution is suggested. Additionally, we investigated internet users, who represent a large group of birdwatchers who should not be neglected by future studies.

Funding: The study received no formal funding. We acknowledge support by Gips Schüle Stiftung.

Institutional Review Board Statement: The study was granted permission by the Social Science and Economics Faculty of the University of Tuebingen (\#number: Az A2.5.4.-113_aa).

Informed Consent Statement: Informed consent was obtained from all subjects involved in the study (details see methods).

Data Availability Statement: Data/code openly available in a public repository that issues datasets with DOIs. The data will be uploaded on the Open Science Framework after acceptance https: //osf.io/rn72z/.

Acknowledgments: I am grateful to Naomi Staller for establishing and maintaining the survey website, and many people from different organizations and website that helped to promote the study. Nadine Kalb helped with cluster assessment analyses.

Conflicts of Interest: The author declares no conflict of interest.

\section{References}

1. Scott, D.; Shafer, C.S. Recreational specialization: A critical look at the construct. J. Leis. Res. 2001, 33, 319-343. [CrossRef]

2. Bentz, J.; Lopes, F.; Calado, H.; Dearden, P. Managing marine wildlife tourism activities: Analysis of motivations and specialization levels of divers and whale watchers. Tour. Manag. Perspect. 2016, 18, 74-83. [CrossRef]

3. Kellert, S.R. Birdwatching in American society. Leis. Sci. 1985, 7, 343-360. [CrossRef]

4. Bryan, H. Leisure value systems and recreation specialisation. J. Leis. Res. 1977, 9, 174-187. [CrossRef]

5. Bryan, H. Recreation specialization revisited. J. Leis. Res. 2000, 32, 18-21. [CrossRef]

6. Lee, J.H.; Scott, D. Measuring birding specialization: A confirmatory factor analysis. Leis. Sci. 2004, 26, 245-260. [CrossRef]

7. Hvenegaard, G.T. Birder specialization differences in conservation involvement, demographics, and motivations. Hum. Dimens. Wildl. 2002, 7, 21-36. [CrossRef]

8. Kyle, G.; Absher, J.; Norman, W.; Hammitt, W.; Jodice, L. A modified involvement scale. Leis. Stud. 2007, 26, 399-427. [CrossRef]

9. Kim, S.S.; Scott, D.; Crompton, J.L. An exploration of the relationships among social psychological involvement, behavioral involvement, commitment, and future intentions in the context of birdwatching. J. Leis. Res. 1997, 29, 320-341. [CrossRef]

10. Cooper, C.B.; Smith, J.A. Gender patterns in bird-related recreation in the USA and UK. Ecol. Soc. 2010, 15, 1-13. [CrossRef]

11. Eubanks, T.L., Jr.; Stoll, J.R.; Ditton, R.B. Understanding the diversity of eight birder sub-populations: Socio-demographic characteristics, motivations, expenditures and net benefits. J. Ecotourism 2004, 3, 151-172. [CrossRef]

12. Harshaw, H.W.; Cole, N.W.; Dayer, A.A.; Rutter, J.D.; Fulton, D.C.; Raedeke, A.H.; Schuster, R.M.; Duberstein, J.N. Testing a continuous measure of recreation specialization among birdwatchers. Hum. Dimens. Wildl. 2021, 1-9. [CrossRef]

13. Lee, S.; Scott, D. Empirical linkages between serious leisure and recreational specialization. Hum. Dimens. Wildl. 2013, 18, 450-462. [CrossRef]

14. Lee, S.; McMahan, K.; Scott, D. The gendered nature of serious birdwatching. Hum. Dimens. Wildl. 2015, 20, 47-64. [CrossRef] 
15. Lessard, S.K.; Morse, W.C.; Lepczyk, C.A.; Seekamp, E. Perceptions of Whooping Cranes among waterfowl hunters in Alabama: Using specialization, awareness, knowledge, and attitudes to understand conservation behavior. Hum. Dimens. Wildl. 2018, 23, 227-241. [CrossRef]

16. McFarlane, B.L. Specialization and motivations of birdwatchers. Wildl. Soc. Bull. 1994, 22, 361-370.

17. McFarlane, B.L. Socialization influences of specialization among birdwatchers. Hum. Dimens. Wildl. 1996, 1, 35-50. [CrossRef]

18. McFarlane, B.L.; Boxall, P.C. Participation in wildlife conservation by birdwatchers. Hum. Dimens. Wildl. 1996, 1, 1-14. [CrossRef]

19. Moore, R.L.; Scott, D.; Moore, A. Gender-based differences in birdwatchers' participation and commitment. Hum. Dimens. Wildl. 2008, 13, 89-101. [CrossRef]

20. Scott, D.; Lee, J.H. Progression, stability, or decline? Sociological mechanisms underlying change in specialization among birdwatchers. Leis. Sci. 2010, 32, 180-194. [CrossRef]

21. Scott, D.; McMahan, K.K. Hard-core leisure: A conceptualization. Leis. Sci. 2017, 39, 569-574. [CrossRef]

22. Scott, D.; Thigpen, J. Understanding the birder as tourist: Segmenting visitors to the Texas Hummer/Bird Celebration. Hum. Dimens. Wildl. 2003, 8, 199-218. [CrossRef]

23. Scott, D.; Baker, S.M.; Kim, C. Motivations and commitments among participants in the Great Texas Birding Classic. Hum. Dimens. Wildl. 1999, 4, 50-67. [CrossRef]

24. Scott, D.; Ditton, R.B.; Stoll, J.R.; Eubanks, T.L., Jr. Measuring specialization among birders: Utility of a self-classification measure. Hum. Dimens. Wildl. 2005, 10, 53-74. [CrossRef]

25. United States Bureau of the Census. National Survey of Fishing, Hunting, and Wildlife-Associated Recreation; (No. 1); U.S. Department of the Interior, Fish and Wildlife Service: Bailey's Crossroads, VA, USA, 1988.

26. Tsaur, S.H.; Liang, Y.W. Serious leisure and recreation specialization. Leis. Sci. 2008, 30, 325-341. [CrossRef]

27. Cheung, L.T.; Lo, A.Y.; Fok, L. Recreational specialization and ecologically responsible behaviour of Chinese birdwatchers in Hong Kong. J. Sustain. Tour. 2017, 25, 817-831. [CrossRef]

28. Costa, A.; Pintassilgo, P.; Matias, A.; Pinto, P.; Guimarães, M.H. Birdwatcher profile in the Ria Formosa Natural Park. Tour. Manag. Stud. 2018, 14, 69-78. [CrossRef]

29. Conradie, N.; Van Zyl, C. Behavioural involvement in avitourism: An international case study. Afr. J. Hosp. Tour. Leis. 2016, 5, 1-26.

30. Frattczak, M.; Sparks, T.H.; Randler, C.; Tryjanowski, P. Circadian preferences of birdwatchers in Poland: Do "owls" prefer watching night birds, and "larks" prefer daytime ones? PeerJ 2020, 8, e8673. [CrossRef] [PubMed]

31. Hermes, J.; von Haaren, C.; Schmücker, D.; Albert, C. Nature-based recreation in Germany: Insights into volume and economic significance. Ecol. Econ. 2021, 188, 107136. [CrossRef]

32. Arlinghaus, R.; Mehner, T. Socio-economic characterisation of specialised common carp (Cyprinus carpio L.) anglers in Germany, and implications for inland fisheries management and eutrophication control. Fish. Res. 2003, 61, 19-33. [CrossRef]

33. Kuentzel, W.F.; Heberlein, T.A. Does specialization affect behavioral choices and quality judgments among hunters? Leis. Sci. 1992, 14, 211-226. [CrossRef]

34. Booth, J.E.; Gaston, K.J.; Evans, K.L.; Armsworth, P.R. The value of species rarity in biodiversity recreation: A birdwatching example. Biol. Conserv. 2011, 144, 2728-2732. [CrossRef]

35. Charrad, M.; Ghazzali, N.; Boiteau, V.; Niknafs, A. NbClust: An R Package for Determining the Relevant Number of Clusters in a Data Set. J. Stat. Softw. 2014, 61, 1-36. [CrossRef]

36. R Core Team. R: A Language and Environment for Statistical Computing; R Foundation for Statistical Computing: Vienna, Austria, 2020; Available online: https:/ / www.R-project.org (accessed on 15 June 2021).

37. Focus.de: Mean age of Germans. 2020. Available online: https://www.focus.de/wissen/mensch/verjuengungstrend-in-derbundesrepublik-durchschnittsalter-sinkt-deutschland-ist-erstmals-seit-26-jahren-juenger-geworden_id_5948844.html (accessed on 1 July 2020).

38. Randler, C. Users of a citizen science platform for bird data collection differ from other birdwatchers in knowledge and degree of specialization. Glob. Ecol. Conserv. 2021, 27, e01580. [CrossRef]

39. Randler, C.; Adan, A.; Antofie, M.M.; Arrona-Palacios, A.; Candido, M.; Boeve-de Pauw, J.; Chandrakar, P.; Demirhan, E.; Detsis, V.; Di Milia, L.; et al. Animal Welfare Attitudes: Effects of Gender and Diet in University Samples from 22 Countries. Animals 2021, 11, 1893. [CrossRef] 